\title{
Shared cognition in childhood anxiety: interpretation bias in preschool children and their parents
}

Article

Accepted Version

Ooi, J., Dodd, H. F. and Walsh, J. (2015) Shared cognition in childhood anxiety: interpretation bias in preschool children and their parents. Journal of Child and Family Studies, 24 (11). pp. 3413-3422. ISSN 1573-2843 doi:

https://doi.org/10.1007/s10826-015-0143-5 Available at https://centaur.reading.ac.uk/40177/

It is advisable to refer to the publisher's version if you intend to cite from the work. See Guidance on citing.

Published version at: http://link.springer.com/article/10.1007/s10826-015-0143-5

To link to this article DOI: http://dx.doi.org/10.1007/s10826-015-0143-5

Publisher: Springer

All outputs in CentAUR are protected by Intellectual Property Rights law, including copyright law. Copyright and IPR is retained by the creators or other copyright holders. Terms and conditions for use of this material are defined in the End User Agreement.

www.reading.ac.uk/centaur 
Central Archive at the University of Reading

Reading's research outputs online 
This is the authors' own version of the following paper:

Shared Cognition in Childhood Anxiety: Interpretation Bias in Preschool Children and Their Parents

Jinnie Ooi • Helen F. Dodd • Judi Walsh

The published version can be found online at:

http://link.springer.com/article/10.1007/s10826-015-0143-5

\section{Acknowledgements}

Thanks to the parents and children who volunteered, and to the relevant gatekeepers at preschools and parent-toddler groups that supported this research and allowed access to the participants. Thanks also to Benjamin Marshall for his assistance in reliability coding.

H. F. Dodd $(\square)$

School of Psychology and Clinical Language Sciences, Harry Pitt Building, Earley Gate, Whiteknights, University of Reading, Reading, RG6 6AL, UK.

J. Ooi • J. Walsh

School of Psychology, University of East Anglia, Norwich, UK. 


\begin{abstract}
Although interpretation bias has been associated with the development and/or maintenance of anxiety, its origins remain unclear. The present study is the first to examine the potential intergenerational transmission of this bias from parents to their preschool-aged children via parental story-telling. A community sample of 50 parent-child pairs was recruited. Parents completed measures of their own trait anxiety and interpretation bias, their child's anxiety symptoms, and a written story-stem measure, to capture the way parents tell their children stories. Interpretation bias was assessed in preschool-aged children (aged between 2 years 7 months and 5 years 8 months) using an extended Story-stem Paradigm. Young children's interpretation bias was not significantly associated with their own anxiety symptoms. Neither was there evidence for a significant association between parent and child interpretation bias or between parent anxiety and the number of stories they ended in a threatening way. However, a significant positive association was found between the number of stories parents ended in a threatening way on the written stories measure and their child's interpretation bias. There was some indication that this effect was stronger for younger children than older children. The results suggest that parental verbal information via storytelling could play a role in the development of interpretation bias in young children.
\end{abstract}

Keywords: interpretation bias, anxiety, cognition, children, parents 


\section{Introduction}

Childhood anxiety disorders are the most prevalent psychological disorders in preadolescent children, with approximately $3-5 \%$ of children younger than 12 years meeting criteria for an anxiety disorder at any given time (Cartwright-Hatton, McNicol, \& Doubleday, 2006). A recent review (Simon, van der Sluis, Muris, Thompson, \& Cartwright-Hatton, 2014) suggested that anxiety in preadolescent children has a negative impact on quality of life, predicting subsequent social and scholastic incompetence in adolescence (Bosquet \& Egeland, 2006), non-completion of schooling (Duchesne, Vitaro, Larose, \& Tremblay, 2008), and lower adaptive functioning (lalongo, Edelsohn, Werthamer-Larsson, Crockett, \& Kellam, 1995). In addition, evidence also suggests that anxiety in early childhood is a major risk factor for subsequent anxiety, as well as other mental health problems later in life, such as aggression (Dallaire \& Weinraub, 2007), affective disorders (Clark, Rodgers, Caldwell, Power, \& Stansfeld, 2007), and oppositional-defiant disorder (Bufferd, Dougherty, Carlson, Rose, \& Klein, 2012). Young children's anxiety problems tend to persist in the absence of any intervention and early treatment is therefore crucial (Simon et al., 2014).

In exploring the origins of childhood anxiety, previous research has shown that anxious parents are more likely to have an anxious child than non-anxious parents (Mancini, van Ameringen, Szatmari, Fugere, \& Boyle, 1996; Weissman, Leckman, Merikangas, Gammon, \& Prusoff, 1984). About one third of this relationship is accounted for by genetics (Gregory \& Eley, 2007), leaving a significant role for the environmental effects of having an anxious parent (Creswell, Cooper, \& Murray, 2010; Hadwin et al., 2006). One way in which parental anxiety might have an environmental effect on children's anxiety is via the intergenerational transmission of biased thinking styles. Interpretation bias refers to a tendency to disproportionately interpret ambiguous situations as threatening (Field, Hadwin, \& Lester, 2011; Hadwin, Garner, \& Perez-Olivas, 2006). This bias may play a role in the onset, and/or maintenance of childhood anxiety disorders (Creswell \& O'Connor, 2011; Dodd, Hudson, Morris, \& Wise, 2012; Vassilopoulos, Banerjee, \& Prantzalou, 2009; Warren, Emde, \& Sroufe, 2000), and it is has been hypothesised that anxious parents may inadvertently transfer their interpretation bias to their child via verbal communication (Creswell et al., 2010; Hadwin et al., 2006).

A growing body of research suggests that children and their parents show similar levels of threat interpretation (Bögels, van Dongen, \& Muris, 2003; Creswell \& O'Connor, 2006; Creswell, Schniering, \& Rapee, 
2005; Creswell, Shildrick, \& Field, 2011), although there is some inconsistency, with other studies failing to find an association (Creswell, O’Connor, \& Brewin, 2006; Gifford, Reynolds, Bell, \& Wilson, 2008). In accordance with the intergenerational transmission hypothesis, it has been proposed that the transfer of verbal information is one pathway by which interpretation bias may be transmitted from parents to children (Field \& Lester, 2010; Hadwin et al., 2006; Muris \& Field, 2010). Early research has found that parental verbal information affects children's interpretation bias and/or anxiety-related responses (Rapee, Dadds, \& Ryan, 1996; Chorpita \& Albano, 1996; Dadds, Barrett, Rapee, \& Ryan, 1996). For instance, parents' anxious verbal information enhanced children's interpretation bias and avoidant responses following family discussions of ambiguous scenarios (Chorpita \& Albano, 1996), although other studies have failed to replicate this effect (Bögels et al., 2003; Cobham, Dadds, \& Spence, 1999).

Furthermore, the nature of verbal information communicated by parents seems to be affected by parental anxiety. Field, Lester, and Cartwright-Hatton (2008) found that when parents were presented with an equal amount of positive, negative, and neutral information about novel animals, their trait anxiety was associated with the level of negativity in the verbal information communicated to their children. Consistent with the above, Muris, van Zwol, Huijding, and Mayer (2010) found that when mothers received ambiguous information about unknown animals, their level of trait anxiety determined the transmission of fear beliefs to their children. Specifically, parents with higher anxiety communicated more threatening stories that in turn instilled greater fear beliefs in their children. Therefore, there is emerging evidence suggesting a potential pathway whereby parental anxiety affects the amount of threat they communicate to their children, which in turn affects their children's interpretation bias (Muris \& Field, 2010; Murray, Creswell, \& Cooper, 2009). It is possible that this transfer of verbal information may play a role in the intergenerational transmission of anxiety, or at least cognitive biases.

To our knowledge, all of the literature examining the intergenerational transmission of interpretation bias has focused on middle to late childhood, with early childhood not considered. As parents have most influence over their children's lives in early childhood (Fox, Henderson, Marshall, Nichols, \& Ghera, 2005) and this is a period when children are learning rapidly, it seems possible that children may be particularly affected by information given to them by their parents at this age. Thus, extending intergenerational transmission of bias research to younger children may be important for understanding the early development of biases. 
As the methods used with older children and adults are not developmentally appropriate for young children, there is a dearth of research examining maladaptive anxiety-related cognitions in young children more broadly. Recent research has begun exploring this crucial gap in the field by piloting a story-stem methodology to assess preschool children's interpretation of ambiguous stories (Dodd, Hudson, Morris \& Wise, 2012). In this study, 131 children aged between 3 years 2 months and 4 years 5 months completed the Story-stem Paradigm by finishing three ambiguous story-stems that were presented to them, with the use of dolls and props. The results showed that clinically anxious young children were more likely to give threatrelated endings to the stories than non-anxious young children. However, the cross-sectional relationship between interpretation bias and child anxiety symptoms, as reported by parents, was not significant. Longitudinal follow-up provided some suggestion that interpretation bias, as assessed using the Story Stem Paradigm, may predict anxiety symptoms over time, with a significant association found with anxiety symptoms at 12-month follow-up but not at two year or five year follow-up. As Dodd et al.'s (2012) research relied on just 3 story-stems, the authors acknowledged the need to extend the number of ambiguous stories to increase the sensitivity of the task to detect potential individual differences in young children's interpretation bias.

The present research had four principal aims: (1) to examine the association between anxiety and interpretation bias in young children using an extended version of the Story-stem Paradigm used by Dodd et al. (2012); (2) to investigate whether parents and their preschool-aged children share similar levels of threat interpretation; (3) to examine whether parental trait anxiety affects parent's tendency to end written stories for their children in a threatening way; and (4) to assess whether young children's interpretation bias is associated with parents' written story endings. The hypotheses evaluated were: (H1) young children's interpretation bias will be significantly related to their anxiety symptoms, $(\mathrm{H} 2)$ parents and their children's interpretation bias will be significantly correlated; $(\mathrm{H} 3)$ parents with higher levels of trait anxiety will end more of their written stories in a threatening way; and ( $\mathrm{H} 4)$ young children's interpretation bias will be significantly correlated with the number of parent written stories that end with threat.

\section{Method}

\section{Participants}


Participants were a community sample of 50 children ( 26 boys) aged 2 years 7 months to 5 years 8 months (Mean age $=4$ years, $S D=6$ months) and their parents (mean age $=35$ years, $S D=5$ months) (45 mothers and 5 fathers). Participants volunteered to take part after hearing about the study via letters and advertising at local preschools and parent-toddler groups, the university's e-bulletin and via friends who had also taken part. A total of three hundred leaflets about the study were distributed at the preschools and parent-toddlers groups. Children with any identified developmental disorders were excluded from the study. In this sample, $94 \%$ of children lived with both parents, most of whom identified as white British (90\%). The majority of parents were either working part-time (46\%) or at home by choice (38\%), while $10 \%$ were working full-time. The majority of families (64\%) reported an above average net household income of $£ 35000$ or above, while $18 \%$ reported a net household income of $£ 15000$ and under. The majority of parents had completed post-school qualifications (90\%).

\section{Measures}

Child anxiety symptoms. Parents completed the Revised Preschool Anxiety Scale (PAS-R; Edwards, Rapee, \& Kennedy, 2010), which assesses anxiety symptoms in young children. The measure has good construct validity, and strong internal consistency, test-retest reliability and cross-informant reliability (Edwards et al., 2010). Internal consistency for the total score in this sample was Cronbach's alpha $=.89$.

Parental anxiety symptoms. Parents completed the trait subscale (STAI-T) of the State-Trait Anxiety Inventory, Form Y-2 (STAI-T; Spielberger, Gorsuch, Lushene, Vagg, \& Jacobs, 1983). The STAI-T is a 20-item selfreport measure that assesses "relatively stable individual differences in anxiety proneness and refers to a general tendency to respond with anxiety to perceived threats in the environment" (Spielberger, Gorsuch and Lushene, 1970, p.3). The STAI-T has relatively high concurrent validity with other measures of anxiety, ranging from .73 - .85, and strong internal consistency and good test-retest reliability (Spielberger et al., 1983). Internal consistency for this sample was Cronbach's alpha $=.92$.

Child interpretation bias. A story-stem methodology was used to assess children's interpretation bias. This methodology has been used in previous research (Dodd et al., 2012) and has demonstrated reasonable success in assessing interpretation bias in young children aged between 3 years 2 months and 4 years 5 months. In the present research, eight ambiguous story-stems (refer to Appendix A) were presented to the 
children and they were asked to complete the story stems verbally, with the help of dolls and additional props. Children's responses were coded using the coding scheme described below. To ensure that the stories captured the range of anxiety typically experienced by young children, stories were selected and constructed based on themes of physical threat, social threat and separation anxiety. The story stems were designed to be ambiguous and to allow for interpretation as either threatening or non-threatening. From the total of eight stories (four physical, two social and two separation), two were adapted from Dodd et al.'s (2011) study, two were adapted from previous research examining interpretation bias in older children (Barrett, Rapee, Dadds \& Ryan, 1996), and four were created for the purposes of this research. To ensure the ambiguity of the story stems, six adult independent raters rated the stories using a 7-point Likert scale ranging from -3 (no threat) to +3 (threat), with a score of 0 indicating ambiguity in the story stems. The ratings reflected ambiguity for all the 8 story stems, with an overall mean of $.08(S D=.65)$.

Parent Written Stories (Verbal Information). To examine the way parents communicated with their children about ambiguous situations, the 8 story-stems described above were also included as a written storystem measure, which asked parents to complete the stories according to how they would tell each one to their child. The responses were coded by the researcher based on the coding scheme described below.

Parental interpretation bias. To measure parents' own interpretation bias, parents completed an interpretation bias measure consisting of 12 ambiguous scenarios (refer to Appendix B); half the scenarios described social situations (e.g. "You're giving a speech. People in the audience start laughing, why?), while the other half described non-social situations (e.g. "Your stomach starts to feel a bit funny on your way into work, why?"). Parents were instructed to imagine that they were experiencing each scenario and to write their interpretation of the scenarios on the questionnaire. Their responses were coded using the same coding scheme described below. The scenarios were adapted from Barrett et al. (1996) and Wisco and NolenHoeksema (2010), and were developed in consultation with experts in the area. To ensure the scenarios were ambiguous, 13 independent adult raters rated the stories using a 7-point Likert scale ranging from -3 (no threat) to +3 (threat), with a score of 0 indicating ambiguity in the story stems. The ratings reflected ambiguity for all the 12 ambiguous scenarios, with an overall mean rating of $-.13(S D=1.09)$.

\section{Procedure}


The School of Social Work and Psychology Research Ethics Committee at the University of East Anglia approved the methods of the study. The 1-hour experimental sessions were conducted either at participants' homes or the University, depending on the parent's preference. Parents provided written informed consent for themselves and their children, while the children provided verbal assent to the procedure of the study. During the session, the parents completed the questionnaires outlined above in a separate room while the children completed the Story-stem Paradigm, which was video-recorded. Families were thanked for their time and a small gift was given to the children.

\section{Coding}

For the three interpretation bias measures (child story-stems, parent interpretation bias measure, and parent written story-stem measure) participants' response to each story/scenario was coded individually for the presence of threat or danger (threat interpretation). A score of 1 was assigned when an interpretation was threatening and a score of 0 was assigned when no threat was present in the interpretation. Items were coded as 'missing' if the responses were ambiguous/unclear, irrelevant to the specific story-stem, or if there was nonresponse/non-compliance from the participants. To ensure that threat bias scores were comparable across participants, the mean number of interpretations coded that were threatening was calculated for each measure, as long as that participant had data available for at least $80 \%$ of the scenarios on the relevant measure. Thus, data were not included in the analyses for any measures where participants had missing data on more than $20 \%$ of the scenarios. More details on the coding and specific examples of responses coded as threat, non-threat and missing for each measure are provided in Appendix C. The first author coded data from all three measures for the 50 parent-child pairs (400 stories for children's story-stems, 400 stories for the written story-stem measure, and 600 scenarios for the parent interpretation bias measure) but was blind to which measures came from the same parent or parent-child pair. To check for reliability, a second coder also coded data from all the three measures for $25 \%$ (13 parent-child pairs) of the randomly selected participant pairs (104 stories for children's story-stems, 104 stories for the written story-stem measure, and 156 scenarios for the parent interpretation bias measure).

Child interpretation bias. Out of a possible total of 400 stories, 115 (29\%) were coded as threat interpretation, 234 (58\%) were coded as non-threat, while 51 (12\%) were coded as missing data. Twelve 
children (24\%) had missing data on more than $20 \%$ of stories, so no score was calculated for these participants. Missing data were due to child task refusal and ambiguity in responses from the children. Inter-rater reliability for children's total threat interpretations was ICC $(2,1)=.99$.

Parental Written Stories (Verbal Information). Out of a total of 400 stories, 48 (12\%) were coded as threat interpretation, $348(87 \%)$ were coded as non-threat, while $5(1 \%)$ were coded as missing data. One parent (2\%) had missing data on more than $20 \%$ of the stories, so no score was available for that participant. Missing data were due to non-response from parents. Inter-rater reliability for the written story-stem measure was $\operatorname{ICC}(2,1)=.76$

Parental interpretation bias. Out of a total of 600 stories, 136 (23\%) were coded as threat interpretation, 463 (77\%) were coded as non-threat, while $1(.17 \%)$ was coded as missing. Missing data were due to non-response from parents. There were no participants with missing data on more than $20 \%$ of the scenarios. Inter-rater reliability for parental interpretation bias was ICC $(2,1)=.78$.

\section{Results}

\section{Data Preparation}

All the variables described above were normally distributed, except for parents' written stories. There was a significant positive skew in the distribution of responses, all analyses involving this variable were therefore bootstrapped, and estimates using 1000 bootstrapped samples are reported. Using a criterion-based z-score methodology, no outliers were identified.

The level of trait anxiety symptoms for both the parents and their children was explored. Independent samples $t$ tests were conducted to examine differences between the means and standard deviations from the normative data and that of the present sample. Parents' anxiety scores $(M=37.78, S D=9.08, N=50)$ were slightly higher than Spielberger et al.'s (1983) normative sample of working adults $(M=34.79, S D=9.22$, $N=451), t(499)=2.17, p=.02, d=.19$. In contrast, the children's anxiety scores in this sample $(M=30.94, S D=$ $15.04, N=50)$ were significantly lower than Edwards et al.'s (2010) normative sample of young children $(M=$ $38.40, S D=19.00, N=764), t(812)=2.72, p=.01, d=.19$. 
There were no significant differences on age, gender or anxiety between children with complete total interpretation bias scores $(N=38)$ and those with incomplete data $(N=12), t(46)=.73, p=.47, d=.10 ; \chi^{2}(1)$ $=.25, p=.61, \varphi=.02 ; t(48)=1.70, p=.09, d=.49$. Note however, that the $p$-value for anxiety approached significance suggesting that the participants with complete interpretation bias data may have been slightly more anxious than those with incomplete data. To ascertain whether the children with missing data may have differed on their interpretation bias, we compared children who had completed more than half of the storystems but not enough for a reliable mean score to be computed ( 5 or 6 stories) $(N=8)$ with those for whom a mean score was available. No significant differences were found between interpretation bias scores, $t(8.25)=$ $-1.01, p=.34, d=-0.70$. We did not include participants who had only completed 4 or less story-stems in this analysis, as we did not feel we could make any valid inference about what their total score might have been.

Lastly, as two of the children in the present sample were younger than 3 years ( 2 years 7 months and 2 years 11 months), the analyses below were first conducted by including all the children in the sample and another by excluding those below three years. Findings from both sets of analyses were comparable so these children are included.

\section{Hypothesis Testing}

To investigate the hypotheses in the present study, Pearson's correlations were conducted first between young children's interpretation bias and their anxiety symptoms ( $\mathrm{H} 1)$, and second between parent and child interpretation bias (H2). No significant association was found between young children's interpretation bias and their anxiety symptoms, $r=-.03, p=.83$. There was a small negative relationship between parent and child interpretation bias, but this was not statistically significant, $r=-.25, p=.13$.

Bootstrapped Pearson's correlations were conducted between parental trait anxiety and parent written stories (H3), followed by parent written stories and children's interpretation bias (H4). No significant association was found between parental trait anxiety and parent written stories, $r=.13, p=.37$. There was a significant relation between parent written stories and children's interpretation bias, $r=.37, p=.02$. To explore this further, we examined whether parent written stories might be associated with child anxiety levels but no significant association was found, $r=.15, p=.30$.

\section{The moderating effect of age and gender}


To examine whether the above findings were moderated by age and/or gender, exploratory analyses were conducted using multiple regression. For each hypothesis, a regression model was constructed that mirrored the relevant correlation above but also included age and gender as predictor variables. All two and three-way interactions were also included. Dependent variables were as follows: Child anxiety (for H1); child interpretation bias (for H2); parent written stories (for H3); children's interpretation bias (for H4). For H1, H2 and $\mathrm{H} 3$ the regression models were not significant, $p>.05$. For $\mathrm{H} 4$, the regression model including all predictors and interactions was significant, $F(7,27)=3.85, M S E=.15, p=.01, R^{2}=.50$. Examination of the coefficients indicated significant main effects of parent written stories, $b=19.92, S E=6.46$, child gender, $b=$ $1.65, S E=.72$, child age, $b=.07, S E=.02$, significant interactions between parent written stories and child age, $b=-.38, S E=.14$, parent written stories and child gender, $b=-9.35, S E=4.04$, child age and child gender, $b=-$ $.03, S E=.01$, and parent written stories, child age, and child gender, $b=.18, S E=.08$. To explore the three-way interaction, bootstrapped Pearson's correlations were conducted between parent written stories and child interpretation bias for the following 4 groups: 2-3 year old boys, 2-3 year old girls, 4-5 year old boys, and 4-5 year old girls. Large correlations were found for girls aged $2-3$ years, $r=.93, p=.00$, and for boys aged 2-3 years, $r=.56, p=.19$, although the latter did not reach significance, the analysis is very underpowered. For both boys and girls aged 4-5 years, there was little evidence of an association between parent stories and child bias, $r=-.05, p=.88, r=.16, p=.69$, respectively. These associations can be seen in Figure 1 .

\section{Discussion}

There is some evidence that school-aged children exhibit similar levels of interpretation bias to their parents (e.g., Barrett et al., 1996; Creswell et al., 2011), and that this bias might be transferred from parents to their children via threatening verbal information (Field et al., 2008; Muris et al., 2010). The present study represents the first attempt to explore whether this intergenerational transfer of interpretation bias might also occur in preschool-aged children.

First, the present study attempted to replicate and extend Dodd et al.'s (2012) baseline findings in a typically developing population. Contrary to the first hypothesis, there was no significant relationship between young children's interpretation bias and their anxiety symptoms. Although Dodd and colleagues found a significant association between interpretation bias and clinical anxiety diagnoses, the correlation between 
child anxiety symptoms and interpretation bias was not significant and was comparable to that found here; $r=$ $-.03, p=.83$, and $r=.13, p=.13$, respectively. It is plausible that this discrepancy in findings between clinical anxiety diagnoses and anxiety symptoms occurs because the link between interpretation bias and anxiety is a feature of clinical anxiety but does not vary with non-clinical individual differences in anxiety scores. As the present study adopted a community sample, the lack of variation in participants' anxiety scores may have limited the scope for detecting a significant effect. Nevertheless, given the comparable correlations with Dodd and colleagues, as mentioned above, this does not provide a complete explanation. One point that is an important consideration for the present research is that we don't yet know how stable any association between interpretation bias and anxiety is in young children or, indeed, how stable bias as assessed using the story-stem task is. Field and Lester (2010) proposed that biases in information processing may not be present or fully developed in young children until certain cognitive, emotional and social skills necessary to sustain these biases have developed. In line with this, it is plausible that cognitive biases initially develop during the preschool years but that the association with anxiety isn't stable until later in childhood. For instance, during early childhood, children's capacity to anticipate negative outcomes (Muris, Merckelbach, Meesters, \& van den Brand, 2002) and to adequately recognize that a problem may have multiple possible outcomes in the context of ambiguity (Horobin \& Acredolo, 1989) develops significantly and these factors may affect the emergence of an anxiety-linked interpretation bias. It is also plausible that the inconsistency with previous findings with older children could be due to the fact that anxiety symptoms here were reported by parents using a questionnaire measure; the most convincing associations between anxiety and bias in older children are found when children self-report their anxiety as compared to when parents report on their child's anxiety using a questionnaire measure (e.g. Creswell et al., 2011).

The second aim of the present research was to examine whether parents and their preschool-aged children share similar levels of threat interpretation. Contrary to the second hypothesis, young children's interpretation bias was not significantly correlated with their parent's interpretation bias. Although this is not in keeping with the intergenerational transmission hypothesis, it is consistent with some previous research that has also failed to find this association (Creswell et al., 2006; 2011; Gifford et al., 2008). The lack of association between parent and child interpretation bias could be influenced by the use of different points of view: parents' responses to the scenarios were based on themselves, while children completed the story- 
stems based on the dolls (i.e. Bob or Jane). Additionally, interpretation bias in parents and children were measured using different response methods. To ensure that the task was developmentally appropriate, children completed the story-stems verbally, while parents completed a pencil and paper measure. Moreover, in efforts to incorporate developmentally-relevant themes, children's story-stems were physical (50\%), social (25\%), and separation (25\%) in nature, while parents' interpretation task mainly measured general (50\%) and social (50\%) anxiety. To enable greater comparability across informants, future research could ask children to respond to the story-stems based on their own perspective, as well as develop parallel versions of the interpretation bias task for parents and their young children, as least in terms of content. Further research, ideally using longitudinal methods, could provide clearer insight into the association between parents' and their children's interpretation biases over time and might help to tease apart the potential effect of cognitive maturation on the development of maladaptive cognition in young children.

The third aim was to examine whether parent trait anxiety was associated with the number of written stories they ended in a threatening way when asked how they would tell their child the stories. Results were not consistent with the third hypothesis; there was no evidence for a significant relationship between parental trait anxiety and their written stories. It is possible that parents from a community sample may be more wary about communicating threat to their children, and may be deliberately selective about ending stories in a nonthreatening manner, regardless of their trait anxiety. However, previous research involving community samples suggests that parents who were more anxious indeed told more threatening stories to their older children (Field et al., 2008; Muris et al., 2010). Future research could investigate whether this inhibitory effect may be particularly prominent in parents with young children, possibly due to greater perceived vulnerability of younger children.

As existing research on the effect of parental verbal information on children's interpretation bias predominantly focuses on children aged 7 years and older (Barrett et al., 1996; Chorpita et al., 1996; Dadds et al., 1996; Muris et al., 2010), the final aim of the present study was to investigate whether young children's interpretation bias was linked to their parents' written stories. The results supported the hypothesis, indicating that children's interpretation bias was associated with the amount of threat in parents' written stories. Consistent with previous research, these findings support the idea that parental verbal information might affect preschool children's biases. Although there was no evidence for an association between parents' story- 
telling and children's anxiety symptoms, it is important to consider that Dodd et al. (2012) found that children's interpretation bias predicted child anxiety 12-months later. Thus, parent stories may affect children's interpretation of ambiguity, which may in turn affect their vulnerability for anxiety over time.

Exploratory analyses regarding the possible moderating effects of children's age and gender indicated that parents' written stories were associated with interpretation bias in younger children (2-3 years) but not older children (4-5 years), and that, in younger children, the association was stronger for girls than for boys. There was a very strong significant correlation between parents' written stories and interpretation bias in girls aged 2-3 years, while the correlation for boys of a similar age was large, this did not reach statistical significance given the small sample. This may indicate that younger children are particularly receptive towards parents' verbal information, with girls being more affected than boys. Alternatively, as most of the parent participants were mothers, the association may be stronger when the parent is the same sex as the child; there were not enough fathers in the present sample to explore this question specifically. It is important to note that these findings are very preliminary as this analysis was exploratory and the study was not powered to address these questions. However, they do indicate that there may be some important age and gender effects that could be further explored in future research.

As the present research is cross-sectional, we are unable to draw conclusions about direction of the effects. It remains possible that parents anticipate how their child would tell the story and complete the written story-stem measure with that in mind. To examine causal pathways convincingly, future research could explore the use of the Story-stem Paradigm as an experimental manipulation, focused on training parents to tell their young children stories in a particular way. If children's interpretation bias decreases after parents tell them non-threatening stories, this would provide convincing evidence that parent verbal information can affect children's bias. Ultimately, this could be useful as a preventative intervention, nicely extending recent research (Lau, Pettit \& Creswell, 2013), which demonstrated potential clinical implications for the use of positive parental verbal information in reducing children's (aged 7-11 years) threat interpretation and social anxiety symptoms through story telling.

The main strength of the present study was the focus on preschool-aged children in exploring the intergenerational transmission of interpretation bias, as previous research has almost exclusively focused on 
older children. The preschool years may be crucial for exploring the developmental origins of interpretation bias. The present study is the first to extend the Story-stem Paradigm beyond the three ambiguous stories piloted by Dodd et al. (2012) and to trial the paradigm in an unselected sample.

The research has some limitations, and the results should be interpreted with these in mind. As is the case with other similar research, fathers were underrepresented in this sample. The parent measures (parent interpretation bias and written stories) were predominantly completed by mothers (90\%) even though it is likely that both parents play a role in influencing their child's cognitive biases, necessitating greater inclusion of fathers in future research. Furthermore, it is likely that a number of factors affect children's interpretation bias and the association between parent cognitions and children's bias, including ethnicity, socio-economic status, as well as shared negative experience. The present research was not designed to address these questions and a much larger sample would be required. Nevertheless, this remains an area of interest for future research.

Furthermore, the present study adopted a written story-stem measure instead of requiring parents to tell the stories directly to their children. This variable was measured using a paper and pencil format to maximise the reliability of coding, minimize the child's participation time, and avoid issues relating to the bidirectionality of effects between parents and their children whilst the parents told the stories. It is worth noting that we initially piloted a task where parents told their children the stories directly, after the children had completed their own story-stems. We found that the children could not attend to the task for long enough for us to complete both in a single session so we adapted the procedure to written stories. The drawback of this method is that it is possible the way parents say they would tell their children the stories might not be representative of how they would actually tell the stories. It is also possible that the written stories may tap into other closely related domains of parental cognitions, such as parents' extension of their interpretation bias to situations involving their children (e.g. Lester, Field, \& Cartwright-Hatton, 2012; Lester, Field, Oliver, \& Cartwright-Hatton, 2009) and/or parents' expectation of their children's responses to the ambiguous situations (e.g. Creswell et al., 2011), which have been found to be associated with parents' anxiety and children's interpretation bias and/or anxiety symptoms, respectively. Future studies could clarify some of these possibilities by including a condition requiring parents to tell the stories to a young child who they are not acquainted with, as well as asking children to complete the story-stems based on themselves. 
Finally, caution should be maintained when interpreting the results due to the following issues. The relatively small sample size may have undermined the chance of detecting possible effects due to a lack of statistical power in the present study. A sample of 50 participants provides $98 \%$ power to detect a large effect size, but results suggest that the size of the relationships of interest is modest at best. For the present research, the rate of missing data for young children's interpretation bias was $24 \%$, reducing the total sample size to 38 children with usable data for this variable. This was comparable to Dodd et al.'s (2012) research that had a $30 \%$ missing data rate for the same variable and future research of a similar nature will need to account for the rate of missing data when estimating the appropriate sample size. In addition, the sample may not be entirely representative as the analyses showed moderate effect sizes for group differences in anxiety symptoms and interpretation bias between children with complete total interpretation bias scores and those with missing data, suggesting that children included in the analyses may be more anxious, but have lower threat interpretations, compared to children with missing data. This could be due to greater compliance during the Story-stem Paradigm by children who were more anxious.

The findings of the present research indicate that how parents report they will tell stories to their children is associated with their threat cognitions that have been linked with children's risk for anxiety over time (Dodd et al., 2012). These findings provide some initial suggestion that early interventions might be able to use parental verbal information as a means of changing maladaptive cognitions in at-risk or anxious young children. Accordingly, future efforts could pilot the use of the Story Stem task within an experimental paradigm to evaluate whether positive parental verbal information could be transferred via storytelling and doll-play to young children. 


\section{References}

Barrett, P. M., Rapee, R. M., Dadds, M. M., \& Ryan, S. M. (1996). Family enhancement of cognitive style in anxious and aggressive children. Journal Of Abnormal Child Psychology, 24(2), 187-203.

Bögels, S. M., van Dongen, L., \& Muris, P. (2003). Family influences on dysfunctional thinking in anxious children. Infant and Child Development, 12(3), 243-252. doi: 10.1002/icd.288

Bosquet, M., \& Egeland, B. (2006). The development and maintenance of anxiety symptoms from infancy through adolescence in a longitudinal sample. Dev Psychopathol, 18(2), 517-550. doi: $10.1017 / \mathrm{s} 0954579406060275$

Bufferd, S. J., Dougherty, L. R., Carlson, G. A., Rose, S., \& Klein, D. N. (2012). Psychiatric Disorders in Preschoolers: Continuity From Ages 3 to 6. American Journal of Psychiatry, 169(11), 1157-1164. doi: 10.1176/appi.ajp.2012.12020268

Cartwright-Hatton, S., McNicol, K., \& Doubleday, E. (2006). Anxiety in a neglected population: prevalence of anxiety disorders in pre-adolescent children. Clin Psychol Rev, 26(7), 817-833. doi: 10.1016/j.cpr.2005.12.002

Cartwright-Hatton, S., McNicol, K., \& Doubleday, E. (2006). Anxiety in a neglected population: prevalence of anxiety disorders in pre-adolescent children. Clin Psychol Rev, 26(7), 817-833. doi: 10.1016/j.cpr.2005.12.002

Chorpita, B. F., \& Albano, A. M. (1996). Cognitive processing in children: Relation to anxiety and family influences. Journal of Clinical Child Psychology, 25(2), 170.

Clark, C., Rodgers, B., Caldwell, T., Power, C., \& Stansfeld, S. (2007). Childhood and adulthood psychological ill health as predictors of midlife affective and anxiety disorders: the 1958 British Birth Cohort. Arch Gen Psychiatry, 64(6), 668-678. doi: 10.1001/archpsyc.64.6.668

Cobham, V. E., Dadds, M. R., \& Spence, S. H. (1999). Anxious children and their parents: What do they expect? Journal of Clinical Child Psychology, 28(2), 220.

Creswell, C., \& O'Connor, T. G. (2006). Anxious cognitions in children: An exploration of associations and mediators. British Journal of Developmental Psychology, 24(4), 761-766. doi: $10.1348 / 026151005 \times 70418$ 
Creswell, C., \& O'Connor, T. G. (2011). Interpretation Bias and Anxiety in Childhood: Stability, Specificity and Longitudinal Associations. Behavioural and Cognitive Psychotherapy, 39(02), 191-204. doi: doi:10.1017/S1352465810000494

Creswell, C., Cooper, P. J., \& Murray, L. (2010). Intergenerational transmission of anxious information processing biases. In J. Hadwin \& A. P. Field (Eds.), Information processing biases and anxiety: A developmental perspective (pp. 279-295). Chichester: Wiley-Blackwell.

Creswell, C., Schniering, C. A., \& Rapee, R. M. (2005). Threat interpretation in anxious children and their mothers: comparison with nonclinical children and the effects of treatment. Behaviour Research and Therapy, 43(10), 1375-1381.

Creswell, C., Shildrick, S., \& Field, A. P. (2011). Interpretation of Ambiguity in Children: A Prospective Study of Associations With Anxiety and Parental Interpretations. Journal of Child \& Family Studies, 20(2), 240250. doi: 10.1007/s10826-010-9390-7

Dadds, M., Barrett, P., Rapee, R., \& Ryan, S. (1996). Family process and child anxiety and aggression: An observational analysis. Journal Of Abnormal Child Psychology, 24(6), 715-734. doi: $10.1007 /$ bf01664736

Dallaire, D. H., \& Weinraub, M. (2007). Infant-mother attachment security and children's anxiety and aggression at first grade. Journal of Applied Developmental Psychology, 28(5-6), 477-492. doi: http://dx.doi.org/10.1016/j.appdev.2007.06.005

Dodd, H. F., Hudson, J. L., Morris, T. M., \& Wise, C. K. (2012). Interpretation Bias in Preschool Children at Risk for Anxiety: A Prospective Study. Journal of Abnormal Psychology, 121(1), 28-38. doi: $10.1037 / \mathrm{a} 0024589$

Duchesne, S., Vitaro, F., Larose, S., \& Tremblay, R. (2008). Trajectories of Anxiety During Elementary-school Years and the Prediction of High School Noncompletion. Journal of Youth and Adolescence, 37(9), 1134-1146. doi: 10.1007/s10964-007-9224-0

Edwards, S. L., Rapee, R. M., \& Kennedy, S. (2010). Prediction of anxiety symptoms in preschool-aged children: examination of maternal and paternal perspectives. Journal of Child Psychology and Psychiatry, 51(3), 313-321. doi: 10.1111/j.1469-7610.2009.02160.x 
Field, A. P., \& Lester, K. (2010). Learning of information processing biases in anxious children and adolescents. In J. Hadwin \& A. P. Field (Eds.), Information processing biases and anxiety: A developmental perspective (pp. 253-278). Chichester: Wiley-Blackwell.

Field, A. P., \& Lester, K. J. (2010). Is there room for 'development' in developmental models of information processing biases to threat in children and adolescents? Clin Child Fam Psychol Rev, 13(4), 315-332. doi: $10.1007 / s 10567-010-0078-8$

Field, A. P., \& Lester, K. J. (2010). Is there room for 'development' in developmental models of information processing biases to threat in children and adolescents? Clin Child Fam Psychol Rev, 13(4), 315-332. doi: $10.1007 /$ s10567-010-0078-8

Field, A. P., Hadwin, J. A., \& Lester, K. J. (2011). Information Processing Biases in Child and Adolescent Anxiety: Evidence and Origins. In W. K. Silverman \& A. P. Field (Eds.), Anxiety Disorders in Children and Adolescents: Research, Assessment and Intervention (2nd. ed.). Cambridge: Cambridge University Press.

Field, A. P., Lester, K., \& Cartwright-Hatton, S. (2008). Cognitive-behavioural processes in the intergenerational transmission of fear to children. Paper presented at the Annual Congress of the association for the advancement of behaviour and cognitive therapy.

Fox, N. A., Henderson, H. A., Marshall, P. J., Nichols, K. E., \& Ghera, M. M. (2005). Behavioral inhibition: linking biology and behavior within a developmental framework. Annu Rev Psychol, 56, 235-262. doi: 10.1146/annurev.psych.55.090902.141532

Gifford, S., Reynolds, S., Bell, S., \& Wilson, C. (2008). Threat interpretation bias in anxious children and their mothers. Cognition \& Emotion, 22(3), 497-508. doi: 10.1080/02699930801886649

Gregory, A. M., \& Eley, T. C. (2007). Genetic influences on anxiety in children: what we've learned and where we're heading. Clinical Child and Family Psychology Review, 10(3), 199-212. doi: 10.1007/s10567-007$0022-8$

Hadwin, J. A., Garner, M., \& Perez-Olivas, G. (2006). The development of information processing biases in childhood anxiety: A review and exploration of its origins in parenting. Clinical Psychology Review, 26(7), 876-894. doi: 10.1016/j.cpr.2005.09.004

Horobin, K., \& Acredolo, C. (1989). The Impact of Probability Judgments on Reasoning about Multiple Possibilities. Child Development, 60(1), 183-200. doi: 10.2307/1131084 
Horobin, K., \& Acredolo, C. (1989). The Impact of Probability Judgments on Reasoning about Multiple Possibilities. Child Development, 60(1), 183-200. doi: 10.2307/1131084

Ialongo, N., Edelsohn, G., Werthamer-Larsson, L., Crockett, L., \& Kellam, S. (1995). The Significance of SelfReported Anxious Symptoms in First Grade Children: Prediction to Anxious Symptoms and Adaptive Functioning in Fifth Grade. Journal of Child Psychology and Psychiatry, 36(3), 427-437. doi: 10.1111/j.1469-7610.1995.tb01300.x

Lau, J. Y. F., Pettit, E., \& Creswell, C. (2013). Reducing children's social anxiety symptoms: Exploring a novel parent-administered cognitive bias modification training intervention. Behaviour Research and Therapy, 51(7), 333-337. doi: http://dx.doi.org/10.1016/j.brat.2013.03.008

Lester, K. J., Field, A. P., \& Cartwright-Hatton, S. (2012). Maternal anxiety and cognitive biases towards threat in their own and their child's environment. Journal of Family Psychology, 26(5), 756-766. doi: $10.1037 / \mathrm{a} 0029711$

Lester, K. J., Field, A. P., \& Cartwright-Hatton, S. (2012). Maternal anxiety and cognitive biases towards threat in their own and their child's environment. Journal of Family Psychology, 26(5), 756-766. doi: $10.1037 / \mathrm{a} 0029711$

Lester, K. J., Field, A. P., Oliver, S., \& Cartwright-Hatton, S. (2009). Do anxious parents interpretive biases towards threat extend into their child's environment? Behaviour Research and Therapy, 47(2), 170174. doi: http://dx.doi.org/10.1016/j.brat.2008.11.005

Lester, K. J., Field, A. P., Oliver, S., \& Cartwright-Hatton, S. (2009). Do anxious parents interpretive biases towards threat extend into their child's environment? Behaviour Research and Therapy, 47(2), 170174. doi: http://dx.doi.org/10.1016/j.brat.2008.11.005

Lester, K. J., Seal, K., Nightingale, Z. C., \& Field, A. P. (2010). Are children's own interpretations of ambiguous situations based on how they perceive their mothers have interpreted ambiguous situations for them in the past? Journal of Anxiety Disorders, 24(1), 102-108. doi: http://dx.doi.org/10.1016/j.janxdis.2009.09.004

Mancini, C., van Ameringen, M., Szatmari, P., Fugere, C., \& Boyle, M. (1996). A high-risk pilot study of the children of adults with social phobia. Journal of the American Academy of Child \& Adolescent Psychiatry, 35(11), 1511-1517. doi: 10.1097/00004583-199611000-00020 
Muris, P., \& Field, A. (2008). Distorted cognition and pathological anxiety in children and adolescents. Cognition \& Emotion, 22(3), 395-421.

Muris, P., \& Field, A. P. (2010). The Role of Verbal Threat Information in the Development of Childhood Fear. “Beware the Jabberwock!”. Clinical Child and Family Psychology Review, 13(2), 129-150.

Muris, P., Merckelbach, H., Meesters, C., \& van den Brand, K. (2002). Cognitive Development and Worry in Normal Children. Cognitive Therapy and Research, 26(6), 775-787. doi: 10.1023/A:1021241517274

Muris, P., Merckelbach, H., Meesters, C., \& van den Brand, K. (2002). Cognitive Development and Worry in Normal Children. Cognitive Therapy and Research, 26(6), 775-787. doi: 10.1023/A:1021241517274

Muris, P., van Zwol, L., Huijding, J., \& Mayer, B. (2010). Mom told me scary things about this animal: Parents installing fear beliefs in their children via the verbal information pathway. Behaviour Research and Therapy, 48(4), 341-346. doi: http://dx.doi.org/10.1016/j.brat.2009.12.001

Murray, L., Creswell, C., \& Cooper, P. J. (2009). The development of anxiety disorders in childhood: An integrative review. Psychological Medicine, 39(9), 1413-1423. doi: 10.1017/s0033291709005157

Rapee, R. M., Schniering, C. A., \& Hudson, J. L. (2009). Anxiety Disorders During Childhood and Adolescence: Origins and Treatment Annual Review of Clinical Psychology (Vol. 5, pp. 311-341). Palo Alto: Annual Reviews.

Simon, E., van der Sluis, C., Muris, P., Thompson, E., \& Cartwright-Hatton, S. (2014). Anxiety in preadolescent children: What happens if we don't treat it, and what happens if we do? Psychopathology Review, $1(1), 28-50$.

Spielberger, C. D., Gorsuch, R. L., Lushene, R., Vagg, P. R., \& Jacobs, G. A. (1983). State-Trait Anxiety Inventory for adults: Manual and sample. Palo Alto, CA: Mind Garden, Inc.

Vassilopoulos, S. P., Banerjee, R., \& Prantzalou, C. (2009). Experimental modification of interpretation bias in socially anxious children: Changes in interpretation, anticipated interpersonal anxiety, and social anxiety symptoms. Behaviour Research and Therapy, 47(12), 1085-1089. doi: http://dx.doi.org/10.1016/j.brat.2009.07.018

Warren, S. L., Emde, R. N., \& Sroufe, L. A. (2000). Internal representations: predicting anxiety from children's play narratives. Journal of the American Academy of Child \& Adolescent Psychiatry, 39(1), 100-107. doi: 10.1097/00004583-200001000-00022 
Weissman, M. M., Leckman, J. F., Merikangas, K. R., Gammon, G. D., \& Prusoff, B. A. (1984). Depression and anxiety disorders in parents and children. Results from the Yale family study. Archives of General Psychiatry, 41(9), 845-852.

Wisco, B. E., \& Nolen-Hoeksema, S. (2010). Interpretation bias and depressive symptoms: The role of selfrelevance. Behaviour Research and Therapy, 48(11), 1113-1122. 


\section{Appendix A}

\section{Children's Interpretation Bias Measure (Ambiguous Story-Stems)}

1. This is the park. Here is the family walking in the park. Look, there is this high high rock. Jane wants to climb the rock.

2. Look. These children are playing a fun game. Jane wants to join in. She is getting close. It looks like the children are laughing.

3. This is the park. Jane is playing alone. A group of kids walk towards Jane.

4. Jane and mum are standing by the pavement. They want to cross a busy street to go to the park. There are many cars passing by.

5. Susan is having a fun party at her house. Jane wants to go to the party. Mum is busy so she drops Jane at the party. Mum is about to drive away.

6. Mum and Dad are going out for the night. Susan, the babysitter will stay home with Jane. Mum and Dad are about to leave the house.

7. Mum and Jane are swimming in the pool. They are holding hands. Jane lets go of mum's hands.

8. Jane is at the park. Suddenly, a dog runs towards her. 


\section{Appendix B}

\section{Parent Interpretation Bias Measure (Ambiguous Scenarios)}

1. It's your second week on the job. Your boss stops by your desk in the early afternoon and asks you to come to his office later that day. Why does your boss want to see you?

2. Your child's teacher calls during the day when your child is at school. Why are they calling?

3. You're lying in bed at night when you hear a noise, what might it be?

4. You're on a plane and the pilot tells the passengers to return to their seats and fasten their seatbelts, why?

5. Your stomach starts to feel a bit funny on your way into work, why?

6. You reach into your bag to get your mobile phone out and you can't find it, why?

7. A friend calls and leaves you a voicemail saying, "Give me a call. I need to speak to you. It's important." What does he/she want to talk to you about?

8. You are having a party for your birthday and half an hour after it started, there's still only a few people there, why?

9. You walk into a party and people turn to look at you, why?

10. You see two of your closest friends at the shopping centre together. They didn't tell you they were going. Why?

11. You're walking down the street, and you see one of your friends coming the other way with a group of people. You wave, but your friend doesn't respond. Why?

12. You're giving a speech. People in the audience start laughing. Why? 


\section{Appendix C}

\section{Coding Scheme Examples}

\section{Threat}

Responses with mild or strong presence of danger

Child examples: Falls down from rock, gets hit by car, dog bites child

Parent examples: Child is ill/hurt at school, audience laughing because he/she said something wrong

\section{Non-Threat}

Responses without the presence of danger

Child examples: Jumps down from rock, crosses to the other side of the road, strokes and rides on dog Parent examples: Child forgot lunch box at school, audience laughing because he/she told a joke

\section{Missing}

Responses that are unclear, irrelevant or non-compliance/non-response to task or don't know Child examples: Child blasts off in a space ship from rock, child doesn't know what happens in the situation

Parent examples: Friend called because she is pregnant, Don't know why the boss wants to see him/her 


\section{Figure Caption}

Figure 1. The moderating effect of child age and gender on the association between parent written stories and child interpretation bias. A: Children aged 2-3 years. B: Children aged 4-5 years. 


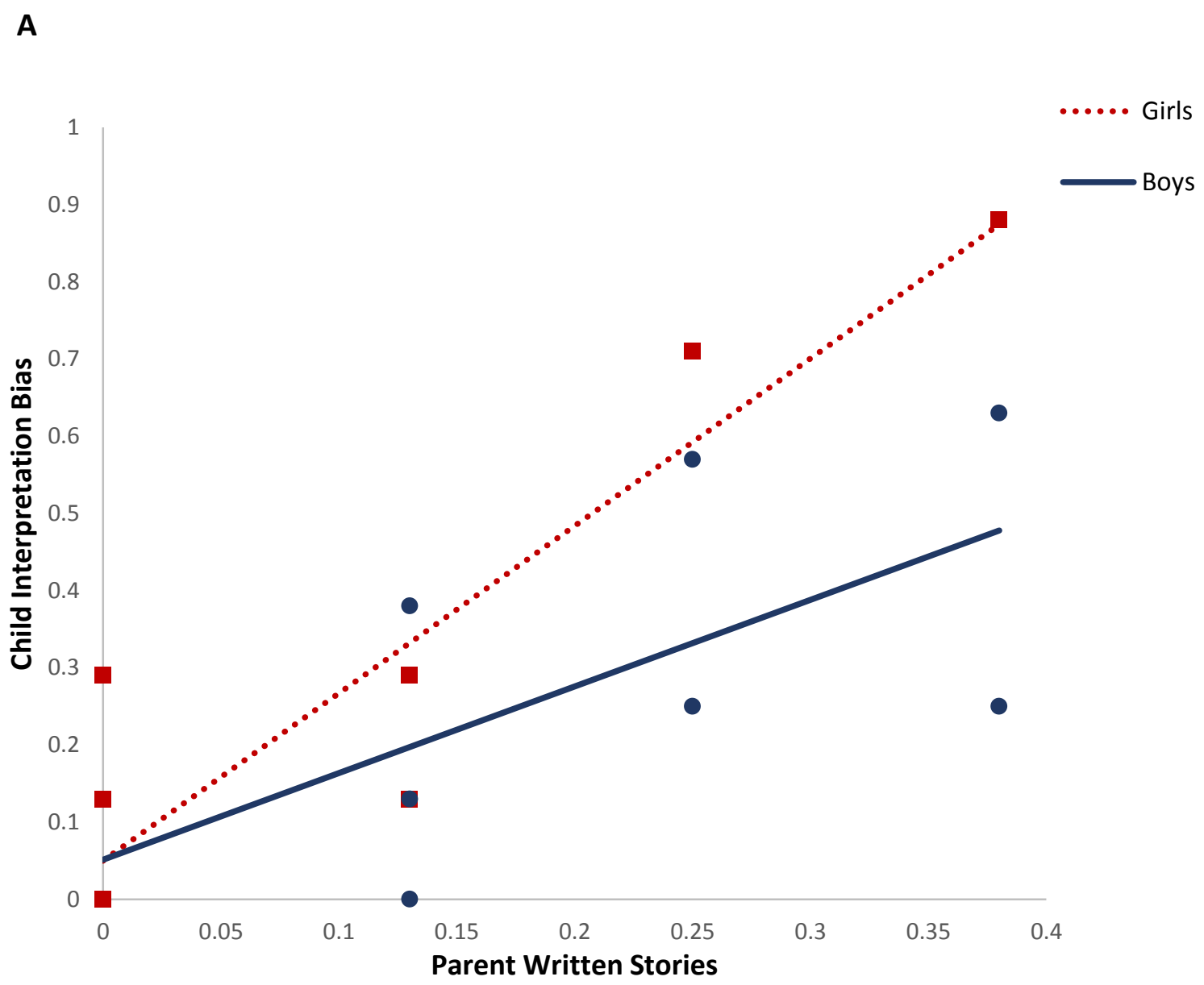




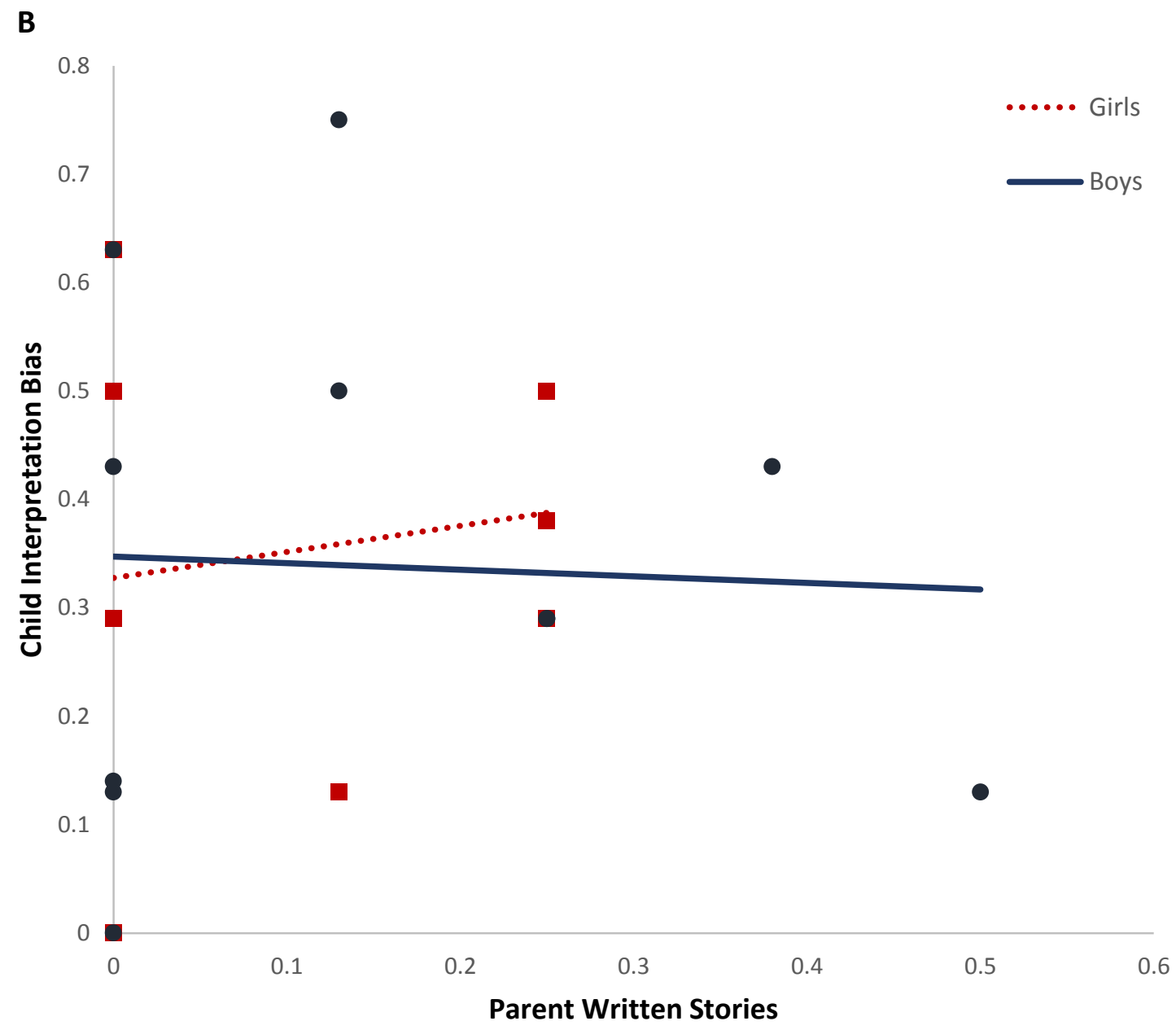

